\title{
Symptoms, airway responsiveness, and exposure to dust in beech and oak wood workers
}

Abraham B Bohadana, Nicole Massin, Pascal Wild, Jean-Paul Toamain, Sandrine Engel, Pierre Goutet

\begin{abstract}
Objectives-To investigate the relation between levels of cumulative exposure to wood dust and respiratory symptoms and the occurrence of bronchial hyperresponsiveness among beech and oak workers. Methods-114 Male woodworkers from five furniture factories and $\mathbf{1 3}$ male unexposed controls were examined. The unexposed control group was supplemented by 200 male historical controls. Statistical analyses were performed excluding and including the historical controls. Dust concentration was measured by personal sampling methods. Cumulative exposure to dust was calculated for each woodworker by multiplying the duration of the work by the intensity of exposure (years.mg/m $\mathbf{m}^{3}$ ). Bronchial hyperresponsiveness was assessed by the methacholine bronchial challenge test. Subjects were labelled methacholine bronchial challenge positive if forced expiratory volume in 1 second $\left(F E V_{1}\right)$ fell by $\geqslant 20 \%$. The linear dose-response slope was calculated as the last dose divided by the total dose given. Results-443 Dust samples were collected. The median cumulative exposure to dust was 110 years. $\mathrm{mg} / \mathrm{m}^{3}$ with lower and upper quartiles at 70 and 160 years. $\mathrm{mg} / \mathrm{m}^{3}$ Overall, no declines in $\mathrm{FEV}_{1}$ and forced vital capacity (FVC) were found with increasing exposures. A dose-response relation was found between intensity of exposure on the one hand, and sore throat, increased prevalence of positive methacholine bronchial challenge tests, and steeper dose-response slope, on the other. Conclusion-Exposure to oak and beech dust may lead to the development of sore throat and bronchial hyperresponsiveness.

(Occup Environ Med 2000;57:268-273)
\end{abstract}

Keywords: bronchial hyperresponsiveness; wood dust; beech; oak

Chimie de l'Est,

Vandoeuvre-lès-Nancy,

France

P Goutet

Correspondence to:

Dr A B Bohadana,

INSERM, Unité 420,

Épidémiologie Santé Travail,

Faculté de Médecine, BP

184-9, Avenue de la Forêt de

Haye, 54505

Vandoeuvre-lès-Nancy,

Cedex, France

email abraham.bohadana $a$

nancy.inserm.fr

Accepted 20 December 1999 identified plicatic acid as the chemical compound in the dust responsible for the asthmatic reaction, and showed that only half the workers
The association between occupational exposure to wood dust and asthma has long been Among the various species of red cedar (Thuja plicata) (3-14 $^{3}$ has been extensively studied. In a pair of benchmark papers, Chan-Yeung et $a P^{-7}$ described the clinical pictures and natural history of cedar asthma, who leave a job because of cedar asthma become asymptomatic, whereas the remaining half continue to experience recurrent attacks of asthma.

Exposure to wood dust can cause adverse respiratory effects which are independent of asthma. In 1982, Chan-Yeung et $a l^{8}$ carried out an epidemiological study of sawmill cedar workers and compared the findings with those of office workers not exposed to respiratory pollutants. They found that cedar workers had significantly higher prevalence of chronic respiratory symptoms and lower lung function compared with office workers. These persisted even after asthmatic workers (wheezers) were excluded from the analysis. Subsequent examinations, carried out over an 11 year time span, showed that sawmill cedar workers had significantly greater decline in forced expiratory volume in 1 second $\left(\mathrm{FEV}_{1}\right)$ and forced vital capacity (FVC) than office workers and that a dose-response relation existed between the intensity of exposure and the annual decline in FVC. $^{14}$

In woodworkers, the development of either variable or fixed airflow obstruction depends on predisposing host factors and environmental factors, especially the nature and intensity of exposure to dust. In 1995, we started a longitudinal survey of bronchial hyperresponsiveness in furniture workers exposed to beech and oak dust, a matter on which there is virtually no information in the epidemiological literature. Our purpose was to examine the possible relation between symptoms and bronchial hyperresponsiveness and intensity of chronic exposure measured objectively. In this report we present the results from the initial (cross sectional) survey.

\section{Subjects and methods}

The study we report on was a cross sectional survey of male employees, comprising the workforce at five wooden furniture factories processing mainly beech (Fagus $s p$ ) and oak (Quercus $s p$ ). The factories were situated in eastern France, within a radius of $40 \mathrm{~km}$ from the city of Neufchateau. Except for salesmen, all current male woodworkers were invited to participate in the study: $135(92.7 \%$ of the workforce) accepted this invitation. Excluded from the study were those subjects who had never been exposed to wood dust but only to vapours or dust from varnish $(n=7)$. An additional group of 14 subjects was also excluded because $(a)$ they were unable to perform pulmonary function tests correctly, $(b)$ because of a history of previous exposure to 
substances known to induce bronchial hyperresponsiveness-for example, flour dust - and (c) they had experienced a possible past exposure to wood dust or varnish which could not be assessed adequately. This left a total of 114 exposed workers. As our aim was to examine the occurrence of pulmonary abnormalities as a function of exposure, a homogeneous split of the sample across the observed range of exposure was planned. The control population from nearby factories was a group of 13 unexposed male workers of similar socioeconomic status, who were examined in the course of the study; they were supplemented by 200 male historical controls, the data for whom had been collected by our team in the years 1991-3 for former studies. ${ }^{15}$ The socioeconomic status of the historical controls was similar to that of workers in the present study; they represented $95 \%$ of the workforce at pollution free workshops of the following industries: glass making $1(\mathrm{n}=48)$; glass making 2 $(n=24)$; glass making $3(n=19)$; electrical engineering $(n=6)$; caterers $(n=9)$; food distribution $(n=27)$; stationery $(n=27)$; and salt packing $(n=40)$. Moreover, they were examined according to a protocol identical to that used in this study including pulmonary function and methacholine challenge test, which were carried out by the same experienced technician with the same equipment.

Examinations were carried out between November 1995 and April 1996. Written, informed consent was given by all subjects. Information was obtained on age, working hours a day, working duration, and occupational history. The prestudy characteristics of the study group and historical controls are shown in table 1 .

\section{MONITORING EXPOSURE}

Measurement of concentrations of airborne dust was carried out by an industrial hygienist from our institution (Laboratoire Interrégional de Chimie de l'Est) on several occasions from 1986 to 1995 . During each survey, a work site inspection was conducted which included assessments of the types and layout of woodworking machinery, local exhaust ventilation, and wood use. Closed face filter holders (Millipore, MA, USA) housing preweighed $37 \mathrm{~mm}$ diameter glass microfibre filters $(\mathrm{GF} / \mathrm{C}$, Whitman) were used. The cassettes were connected to portable, battery operated sampling pumps, sampling at flow rates of $11 . \mathrm{min}^{-1}$. The average inhalable particulate concentration $\mathrm{mg} / \mathrm{m}^{3}$ was

Table 1 Anthropometric characteristics and smoking habits of the study group and historical controls

\begin{tabular}{lcc}
\hline Variable & $\begin{array}{l}\text { Men } \\
(n=127)\end{array}$ & $\begin{array}{c}\text { Historical controls } \\
(n=200)\end{array}$ \\
\hline Age (y) & $41(11)$ & $39(9)$ \\
Height (cm) & $174(7)$ & $174(6)$ \\
Weight (kg) & $78(13)$ & $76(10)$ \\
Smoking: & $38(30)$ & $48(24)$ \\
$\quad$ Non-smokers (n (\%)) & $34(27)$ & $54(27)$ \\
Ex-smokers (n (\%)) & $18(18)$ & $14(10)$ \\
Tobacco consumption (pack-years, mean (SD)) & $55(43)$ & $98(49)$ \\
Current smokers (n (\%)) & $15(13)$ & $16(11)$ \\
$\quad$ Tobacco consumption (pack-years, mean (SD)) & $23(11)$ & $16(9)$
\end{tabular}

Results are given as means (SD) except where indicated. measured from the increased filter mass (Mettler M3 microbalance) and rates and duration of airflow. Care was taken to avoid the collection of "inertials" - that is large particles propelled from high speed machines during sampling.

RESPIRATORY HEALTH

Medical history

Detailed histories of respiratory diseases and smoking habits were recorded in a two part questionnaire The first was a modified version of the European Coal and Steel Community questionnaire on respiratory symptoms ${ }^{16}$ which was given by an experienced physician. Chronic bronchitis was defined as cough and phlegm for at least 3 months each year for not less than 2 successive years. The term chronic cough and/or phlegm was used to define subjects complaining of chronic cough or phlegm regardless of duration: thus, it encompassed both those subjects who fulfilled the criteria for chronic bronchitis and those who did not. Bouts of bronchitis was the term coined to define those subjects who answered yes to the question: "Have you ever experienced an increase in the severity of cough and in the volume of sputum production of at least 3 weeks duration during the past 3 years?". Dyspnoea on exertion was considered to be present when the subjects complained of breathlessness while walking up a slight hill. Adult asthma was defined as asthma which has been diagnosed by a physician at age $\geqslant 16$.

The second part of the questionnaire asked for acute irritant symptoms that the subjects attributed directly to their work. They were considered to be present when the subject answered affirmatively to the questions: "Have you ever had complaints at work of red (burning) (weary) eyes ?"; "Have you ever had complaints at work of a runny (burning) nose ?"; "Have you ever had complaints at work of a sore throat?"; and "Have you ever had complaints at work of a dry (irritant) cough?". A positive answer to these questions should be followed to a positive answer to the question: "Do these complaints disappear when you leave work (evenings, weekends, holidays)?"

Non-smokers were defined as subjects who had never regularly smoked $\geqslant 1$ cigarette a day or had smoked $\geqslant 1$ cigarette a day for $<1$ year. Current smokers were defined as subjects who reported regular smoking of $\geqslant 1$ cigarette a day for $\geqslant 1$ year. Ex-smokers were subjects who reported smoking $\geqslant 1$ cigarette regularly in the past but who had stopped smoking at least 1 year before the study.

\section{Pulmonary function tests}

Spirometry was carried out by the same experienced technician (JPT), with an electronic spirometer (Spiro-Analyzer ST 300, Fukuda Sangyo, Tokyo, Japan). The following indices were obtained by the subject expiring forcefully and maximally after a maximal inspiratory manoeuvre: FVC, $\mathrm{FEV}_{1}$, and maximal expiratory flows at various lung volumes. At baseline each subject performed $\geqslant 3$ reproducible forced expiratory manoeuvres (within 5\% for 
FVC and $\mathrm{FEV}_{1}$ ); thereafter only two reproducible curves were required. The curve with the highest sum of FVC+FEV 1 was used for statistical analysis. The results were expressed as the difference between the observed and predicted values of the European Respiratory Society. ${ }^{17}$

\section{Bronchial responsiveness}

As the examinations were carried out during workshifts, an abbreviated version of the methacholine bronchial challenge test was used. ${ }^{18}$ The technique has been described previously. ${ }^{19} 20$ Two different dose schedules were outlined for subjects with either slightly abnormal lung function or normal lung function, respectively. After baseline spirometry the subject inhaled an aerosol of normal saline, then spirometry was repeated. In subjects whose baseline spirometry was normal and whose $\mathrm{FEV}_{1}$ fell by $<10 \%$ after the inhalation of normal saline, three cumulative doses of methacholine $(0.5,2.5$, and $7.5 \mu \mathrm{mol})$ were given with an inhaler (Mediprom FDC 88 Paris, France) delivering doses of $0.5 \mu \mathrm{mol}$ of methacholine per breath. The system is equipped with a nebuliser (De Vilbiss 5610 D) delivering particles $3 \mu \mathrm{m}$ in diameter. A noseclip was worn and the aerosol inhaled through the mouth slowly. Then the breath was held for 5 seconds. Spirometry was performed in the sitting position, before and 3 minutes after the inhalations of methacholine. The challenge test was discontinued either after the inhalation of the third dose of methacholine or if the $\mathrm{FEV}_{1}$ fell by $\geqslant 20 \%$ below the baseline value. Subjects whose $\mathrm{FEV}_{1} / \mathrm{FVC}$ was $\leqslant 80 \%$, baseline $\mathrm{FEV}_{1} \leqslant 70 \%$, and whose $\mathrm{FEV}_{1}$ fell by $<10 \%$ after saline, were given an initial dose of methacholine of only $10 \mu \mathrm{g}(0.05 \mu \mathrm{mol})$.

Subjects who experienced a fall in $\mathrm{FEV}_{1}$ of $\geqslant 20 \%$ were classified as having a positive methacholine bronchial challenge test. As it could be anticipated that many subjects would fail to experience this specific response, an additional non-censored index of responsiveness was calculated-namely, the linear two point dose-response slope as proposed by O'Connor et al. ${ }^{21}$ The dose-response slope was calculated as the ratio of the percentage fall in $\mathrm{FEV}_{1}$ at the last dose: the total dose of methacholine ( $\mu \mathrm{mol})$ given.

ETHICS

The study was approved by the local medical ethics committee.

Table 2 Measurements of airborne concentrations of wood dust $\left(\mathrm{mg} / \mathrm{m}^{3}\right)$ by job description

\begin{tabular}{|c|c|c|c|c|c|c|}
\hline fob description & $n$ & $\begin{array}{l}\text { Mean } \\
\left(\mathrm{mg} / \mathrm{m}^{3}\right)\end{array}$ & $\begin{array}{l}\text { Minimum } \\
\left(\mathrm{mg} / \mathrm{m}^{3}\right)\end{array}$ & $\begin{array}{l}\text { Maximum } \\
\left(\mathrm{mg} / \mathrm{m}^{3}\right)\end{array}$ & $\begin{array}{l}\text { Geometric } \\
\text { mean } \\
\left(\mathrm{mg} / \mathrm{m}^{3}\right)\end{array}$ & $\begin{array}{l}\text { Geometric } \\
S D\end{array}$ \\
\hline \multicolumn{7}{|c|}{ Without local exhaust ventilation: } \\
\hline Other than sanding $\star$ & 56 & 5.51 & 0.43 & 36.09 & 3.5 & 2.47 \\
\hline Sandingt & 57 & 12.74 & 0.76 & 61.44 & 7.86 & 2.01 \\
\hline \multicolumn{7}{|c|}{ With local exhaust ventilation: } \\
\hline Other than sanding ${ }^{\star}$ & 177 & 4.08 & 0.11 & 24.0 & 2.43 & 2.80 \\
\hline Sandingt & 153 & 8.34 & 0.01 & 131 & 4.48 & 3.47 \\
\hline
\end{tabular}

${ }^{\star}$ Includes handling various types of saws, planing machines, mortising, tenoning, drilling machines, spindle moulding, slotting and milling machines.

tIncludes both manual and mechanical sanding operations.
STATISTICAL ANALYSIS

Statistical analysis was carried out with the SAS statistical software. ${ }^{22}$ Multiple logistic regression analyses were used to assess the effect of the exposure on the symptoms and the presence of a positive methacholine bronchial challenge test while adjusting for the possible confounding factors, especially smoking. Multiple linear regression was used to describe the effect of exposure on the baseline spirometric variables (controlling for smoking), and on the transformed dose-response slope adjusted on baseline $\mathrm{FEV}_{1}$ and age. The transformation we used $\left(1 /\left(\%\right.\right.$ fall $\left.\left.\mathrm{FEV}_{1} / \mu \mathrm{mol}+2.5\right)\right)$ was applied to normalise its statistical distribution in view of multiple regression analyses. This transformation was found to be optimal for a large unexposed population. ${ }^{19}$ Thus, a value of 0.25 corresponds to a fall in $\mathrm{FEV}_{1}$ of $1.5 \%$ per $\mu \mathrm{mol}$ of methacholine, whereas a value of 0.30 corresponds to a fall in $\mathrm{FEV}_{1}$ of $0.8 \%$ per $\mu \mathrm{mol}$ of methacholine. The stability of the variance and approximate linearities in the linear models were checked on residual plots.

To show possible quantitative trends with increasing cumulative exposure to dust, the raw data are displayed in six exposure groups: historical controls, controls collected in the course of the present data collection with no exposure and four groups labelled of equal size and increasing cumulative exposure to dust. However, all trends in the regression analyses were fitted as linear continuous cumulative exposure to dust and thus independent of this grouping.

Two series of statistical analyses were performed excluding and including historical controls. The analyses incorporating historical controls were done in the context of so called mixed models with the PROC MIXED program. ${ }^{22}$ These analyses acknowledge that there may be a between study heterogeneity which is explicitly taken into account as a between population variance. Details and a discussion of this statistical model in this context are presented in a recent paper. ${ }^{15}$

\section{Results}

EXPOSURE ASSESSMENTS

A total of 443 personal time weighted average (TWA) samples were collected between 1986 and 1996 in 28 similar wooden furniture factories (including three of those in this study) located in the same area, and using the same types of wood. A detailed analysis of these exposure data by machine showed that: (a) sanding operations were consistently associated with higher exposure levels; $(b)$ exhaust ventilation resulted in roughly dividing the exposure data by two; (c) all other tasks resulted in roughly comparable exposure intensities; and (d) no systematic differences between factories resulted after taking into account sanding and exhaust ventilation (table 2). On the basis of these measurements, each job was assigned an estimated dust exposure based on the mean value of all dust measurements for that job. Thus, an estimated dust exposure of $13 \mathrm{mg} / \mathrm{m}^{3}$ was assigned to all workers performing sanding operations in areas 
Table 3 Prevalence of chronic respiratory and irritant symptoms (n (\%)) in historical controls (HC) and male workers stratified by exposure to wood dust expressed in terms of the cumulative dust exposure index

\begin{tabular}{|c|c|c|c|c|c|c|c|}
\hline \multirow[b]{2}{*}{ Symptoms } & \multirow[b]{2}{*}{$\begin{array}{l}H C \\
n=200\end{array}$} & \multicolumn{5}{|c|}{ Exposure $\left(y \cdot m g / m^{3}\right)$} & \multirow[b]{2}{*}{$p$ Value * } \\
\hline & & $\begin{array}{l}0 \\
n=13\end{array}$ & $\begin{array}{l}\leqslant 70 \\
n=28\end{array}$ & $\begin{array}{l}70-110 \\
n=28\end{array}$ & $\begin{array}{l}110-160 \\
n=25\end{array}$ & $\begin{array}{l}>160 \\
n=33\end{array}$ & \\
\hline Chronic bronchitis & $3(1.5)$ & $1(8)$ & $1(4)$ & $0(0)$ & $1(4)$ & $2(6)$ & $-\dagger$ \\
\hline Cough or phlegm & $20(10)$ & $1(8)$ & $3(10)$ & $3(10)$ & $3(12)$ & $4(12)$ & 0.14 \\
\hline Bouts of bronchitis & - & $0(0)$ & $2(7)$ & $0(0)$ & $1(4)$ & $1(3)$ & -+ \\
\hline Dyspnoea & $33(17)$ & $0(0)$ & $4(14)$ & $1(4)$ & $5(20)$ & $1(3)$ & $-\dot{t}$ \\
\hline Asthma & $5(2.5)$ & $0(0)$ & $2(7)$ & $1(4)$ & $2(8)$ & $1(3)$ & $-t$ \\
\hline Red (burning) eyes & - & $0(0)$ & $1(4)$ & $9(32)$ & $2(8)$ & $4(12)$ & 0.47 \\
\hline Runny nose & - & $0(0)$ & $2(7)$ & $7(25)$ & $6(24)$ & $7(21)$ & 0.10 \\
\hline Sore throat & - & $0(0)$ & $0(0)$ & $2(8)$ & $2(8)$ & $6(18)$ & 0.03 \\
\hline Dry cough & - & $0(0)$ & $0(0)$ & $0(0)$ & $1(4)$ & $2(6)$ & $-\dagger$ \\
\hline
\end{tabular}

${ }^{\star}$ Logistic regression after adjustment for sex, age and smoking.

tSmall size of the samples precluded statistical analysis.

without local exhaust ventilation whereas an estimated dust exposure of $8 \mathrm{mg} / \mathrm{m}^{3}$ was assigned to those in areas with local exhaust ventilation. For the remaining tasks, workers in areas with and without local exhaust ventilation were assigned estimated dust exposures of respectively 4 and $6 \mathrm{mg} / \mathrm{m}^{3}$ whatever the job classification. To assess lifetime exposures the cumulative exposure index was calculated for each woodworker by multiplying the years of work with the assigned exposure intensity (years. $\mathrm{mg} / \mathrm{m}^{3}$ ). For workers who had worked in various workstations the total cumulative exposure was obtained by summing up the cumulative exposure corresponding to each workstation.

The median cumulative exposure to dust was found at 110 years. $\mathrm{mg} / \mathrm{m}^{3}$ - that is, 11 years at a $10 \mathrm{mg} / \mathrm{m}^{3}$ exposure intensity. Of the exposed population $25 \%(n=28)$ had a cumulative exposure to dust $<71$ years. $\mathrm{mg} / \mathrm{m}^{3}$; whereas 33 subjects (33\%) had a cumulative exposure to dust $>162$ years. $\mathrm{mg} / \mathrm{m}^{3}$ which corresponds to about 12 years of sanding without exhaust ventilation.

RESPIRATORY AND IRRITANT SYMPTOMS

The prevalence of symptoms as a function of the cumulative exposure is shown in table 3. Overall, the prevalence of chronic respiratory symptoms tended to be low, ranging from $0 \%$ for chronic bronchitis (group with 70-110 years. $\mathrm{mg} / \mathrm{m}^{3}$ ), bouts of bronchitis (groups with 0 and $70-110$ years. $\mathrm{mg} / \mathrm{m}^{3}$ ), asthma (group 0 years. $\mathrm{mg} / \mathrm{m}^{3}$ ) and dyspnoea (group 0 years.mg/ $\mathrm{m}^{3}$ ) to $12 \%$ for chronic cough or phlegm (groups with $110-160$ and $>160$ years. $\mathrm{mg} / \mathrm{m}^{3}$ ). The prevalence of irritant symptoms tended to be somewhat higher than that of chronic symptoms with maximal values of $32 \%$ for red (burning) eyes in the group with 70-110 years. $\mathrm{mg} / \mathrm{m}^{3}$. However, only the prevalence of sore throat increased significantly with increasing exposure, a finding compatible with a doseresponse relation.

BASELINE LEVEL OF PULMONARY FUNCTION

Table 4 shows the pulmonary function variables of historical controls and woodworkers according to the various classes of cumulative exposure. Overall, the measured values tended to exceed the predicted ones for most variables. In the exposed group the observed excess FVC ranged from 202 to $280 \mathrm{ml}$. As $\mathrm{FEV}_{1}$ tended to increase proportionally more markedly than FVC, the observed $\mathrm{FEV}_{1} / \mathrm{FVC}$ ratio was slightly greater than the predicted one. For maximal expiratory flows, a pattern of high flows at mid-lung volume $\left(\operatorname{VEmax}_{50}\right)$ and low flows at low lung volume $\left(\operatorname{VEmax}_{25}\right)$ was observed: $\operatorname{VEmax}_{50}$ exceeded the predicted one by an amount ranging from 37 (with 0 exposure) to $561 \mathrm{ml} / \mathrm{s}$ (with 0-70 years.mg/ $\mathrm{m}^{3}$ ). For $\operatorname{VEmax}_{25}$, the observed value tended to be generally lower than the predicted one: the observed difference ranged from -230 (with 0 exposure) to $-382 \mathrm{ml} / \mathrm{s}$ (with $<160$ years.mg/ $\mathrm{m}^{3}$ ). In the group with $0-70$ years. $\mathrm{mg} / \mathrm{m}^{3}$, the observed values of $\operatorname{VEmax}_{25}$ slightly exceeded the predicted one. Finally, it is important to notice that no overall relation was found between the respiratory flows (or any other lung function variable) and the cumulative exposure index.

\section{BRONCHIAL RESPONSIVENESS}

The results of the methacholine bronchial challenge test in historical controls and exposed workers are shown in table 5. Overall, a significant relation was found between the two indices of bronchial responsiveness and intensity of exposure. Both the proportion of subjects with a positive methacholine bronchial challenge test (a fall in $\mathrm{FEV}_{1} \geqslant 20 \%$ ) and the steepness of the dose-response slope increased significantly with increasing cumulative exposures, a finding compatible with a doseresponse relation.

\section{Discussion}

The adverse respiratory effects of exposure to wood dust vary according to the wood species. ${ }^{23}$ Although cases of asthma have been described on exposure to oak dust, both this wood and beech are better known for their carcinogenic effects. ${ }^{23}$ In this investigation, we found that occupational exposure to beech and oak dust is associated with non-malignant respiratory illness.

Table 4 Lung function measurements (observed values-predicted values (SD)) in historical controls (HC) and in the study group stratified by exposure to wood dust expressed in terms of the cumulative dust exposure index

\begin{tabular}{|c|c|c|c|c|c|c|c|c|c|c|c|c|c|}
\hline \multirow[b]{2}{*}{ Variable } & \multirow{2}{*}{\multicolumn{2}{|c|}{$H C$}} & \multicolumn{10}{|c|}{ Exposure $\left(y \cdot m g / m^{3}\right)$} & \multirow[b]{2}{*}{$p$ Value ${ }^{\star}$} \\
\hline & & & 0 & & $\leqslant 70$ & & $70-110$ & & $110-1$ & & $>160$ & & \\
\hline $\mathrm{n}$ & 200 & & 13 & & 28 & & 28 & & 25 & & 33 & & \\
\hline FVC ml (SD) & 337 & (555) & 202 & $(442)$ & 217 & $(636)$ & 339 & $(661)$ & 207 & $(718)$ & 280 & $(658)$ & 0.99 \\
\hline $\mathrm{FEV}_{1} \mathrm{ml}(\mathrm{SD})$ & 219 & (533) & 197 & (333) & 281 & $(592)$ & 246 & (641) & 159 & $(686)$ & 176 & $(696)$ & 0.98 \\
\hline $\mathrm{FEV}_{1} / \mathrm{FVC} \%$ & & $(6.3)$ & 3.42 & $(4.8)$ & 5.1 & $(15.1)$ & 1.8 & (6) & & $(6.07)$ & & $(7.32)$ & 0.17 \\
\hline $\operatorname{VEmax}_{50} \mathrm{ml} / \mathrm{s}(\mathrm{SD})$ & 133 & (1532) & 37 & (1161) & 561 & (1284) & 172 & (1589) & 101 & (1648) & 111 & $(1680)$ & 0.59 \\
\hline $\operatorname{VEmax}_{25} \mathrm{ml} / \mathrm{s}(\mathrm{SD})$ & -332 & $(640)$ & -230 & $(470)$ & 21 & $(929)$ & -252 & $(947)$ & -329 & $(726)$ & -382 & $(679)$ & 0.29 \\
\hline
\end{tabular}

*Linear regression after adjustment for smoking. 
Table 5 Bronchial responsiveness in historical controls (HC) and in the study group stratified by exposure to wood dust expressed in terms of the cumulative dust exposure index

\begin{tabular}{|c|c|c|c|c|c|c|c|c|}
\hline \multirow[b]{2}{*}{ Variable } & \multirow[b]{2}{*}{$H C$} & \multicolumn{5}{|c|}{ Exposure $\left(y . m g / m^{3}\right)$} & \multirow[b]{2}{*}{$p$ Value * } & \multirow[b]{2}{*}{$p$ Valuet } \\
\hline & & 0 & $\leqslant 70$ & $70-110$ & $110-160$ & $<160$ & & \\
\hline $\mathrm{n}$ & 200 & 13 & 28 & 28 & 25 & 33 & - & - \\
\hline MBC+ n (\%) & $(10)$ & $1 \quad(8)$ & $(14.3)$ & $(21.4)$ & $(21.4)$ & $(27.3)$ & $0.77 \ddagger$ & $0.002 \ddagger$ \\
\hline DRS (mean (SD)) & $0.28(0.08)$ & $0.31(0.08)$ & $0.27(0.07)$ & $0.25(0.08)$ & $0.25(0.09)$ & $0.24(0.1)$ & $0.04 \Phi$ & $0.014 \$$ \\
\hline
\end{tabular}

${ }^{\star} \mathrm{HC}$ excluded from the analysis.

tHC included in the analysis.

$\ddagger$ Logistic regression after adjustment for baseline $\mathrm{FEV}_{1}$ and age.

\Linear regression after adjustment for $\mathrm{FEV}_{1}$ and age.

$\mathrm{MBC}+=$ decline in $\mathrm{FEV}_{1}$ by $\geqslant 20 \%$; DRS $=1 /\left(\%\right.$ decline in $\left.\mathrm{FEV}_{1} / \mu \mathrm{mol}+2.5\right)$.

In the present study, the furniture workers underwent a heavy exposure to dust. The measured dust concentrations - which ranged from 2.96 to $8.34 \mathrm{mg} / \mathrm{m}^{3}$ for operations with exhaust ventilation and from 4.37 to 12.74 $\mathrm{mg} / \mathrm{m}^{3}$ for those without exhaust ventilationlargely exceeded the $2.5 \mathrm{mg} / \mathrm{m}^{3}$ permissible concentration (for western red cedar dust) in British Columbia, ${ }^{14}$ and the threshold limit value (time weighted average) of $1 \mathrm{mg} / \mathrm{m}^{3}$ adopted in France, ${ }^{24}$ the threshold limit value of $1 \mathrm{mg} / \mathrm{m}^{3}$ for hardwood proposed by the American Conference of Governmental Industry, ${ }^{25}$ or the health based limit of 0.2 $\mathrm{mg} / \mathrm{m}^{3}$ recommended by the Dutch Expert Committee for Occupational Standards (DECOS). ${ }^{26}$

This is the only study in which the association between levels of bronchial responsiveness and measured exposure in oak and beech workers has been evaluated. There are only a few epidemiological studies dealing with bronchial responsiveness and exposure in unselected woodworkers. Chan-Yeung et $a l^{8}$ examined a large sample of cedar mill workers $(n=652)$ and office workers $(n=440)$ and found a higher prevalence of bronchial hyperresponsiveness among cedar workers which increased with the duration of employment compared with the office workers. Subsequently, Vedal et $a l^{11}$ followed up a subsample $(\mathrm{n}=227)$ of the same group of cedar workers who had had bronchial challenge testing performed on at least two occasions over a 2 year period. They found that subjects with persistent bronchial hyperresponsiveness had higher initial estimated exposure to total airborne dust than did office workers. Dahlqvist et $a l^{27}$ evaluated the bronchial responsiveness to methacholine of woodtrimmers $(n=28)$ at a Swedish sawmill and unexposed office workers $(n=19)$. The rate of positive response was greater in the woodtrimmers $(29 \% v 10 \%)$ but the difference was not significant probably due to the small sample size. Finally, more recently, Malmberg et $a l^{28}$ reported the results of a cross sectional survey of bronchial responsiveness and pulmonary function tests in Swedish sawmill workers $(n=169)$ exposed to Scots pine and Norway spruce. They found the airways of the exposed workers (workers inside the sawing area; $n=59$ ) to be more responsive than the airways of unexposed workers (workers outside the sawing area; $n=39$ ). Together with our study, and despite differences in methodology, these studies give support to the idea that a relation exists between bronchial hyperresponsiveness and exposure to wood dust.

The present study showed that the levels of bronchial responsiveness of beech and oak workers increased significantly with increasing intensities of exposure, a finding not paralleled by a similar increase in the prevalence of symptoms of asthma nor a decline in indices of airway patency. One way to explain this set of findings is to invoke selection by the healthy worker effect. The implication is that beech and oak workers with bronchial hyperresponsiveness who develop disabling symptoms or lung function abnormalities related to exposure tend to move to less exposed places or to leave the job altogether, leaving the place to those with varying degrees of responsiveness but few or no symptoms. However, this is only conjecture because of the cross sectional nature of this (initial) survey.

Alternatively, it could be postulated that beech and oak are wood species which contain relatively low concentrations of sensitisers so they would cause increased responsiveness mainly through mechanical irritation. The increased prevalence of sore throat with increasing intensities of exposure is compatible with this explanation. However, the reported association between exposure to either oak ${ }^{29} 30$ or beech ${ }^{31}$ dust and episodes of bronchial asthma suggests that workers may become sensitised as well. Data on the irritant, toxic, and sensitising wood species of commercial value show that oak is rich in catechols, which are the most potent sensitisers from natural sources, whereas beech contains, besides other compounds, sesquiterpene lactones with both sensitising and irritant properties. ${ }^{31}$

The relation between exposure to wood dust and bronchial hyperresponsiveness was examined by deriving a cumulative exposure index in the standard way with quantitative exposure estimates of industry specific job exposure matrices. Such an index was for instance used in a recent study of lifeguards exposed to nitrogen trichloride..$^{32}$ In the present study, the index assumes that the mean dust concentrations found when machining in many factories are representative of the concentrations found when machining in our furniture factories. This assumption is supported by dust measurements carried out by our team over several years (P Gouet, unpublished observations) which showed that, for a given process and working conditions, the dust concentrations linked to two similar machines in two different factories were comparable with one another. 
Giving further support to this assumption is the fact that the pattern of exposure in this study is similar to that reported for other furniture factories. ${ }^{33}$

Notwithstanding these considerations, we think that the possibility of misclassification cannot be ruled out entirely. However, a non-differential (random) misclassification would usually weaken the chance of finding an association existing between exposure and effect. It is therefore unlikely that the association found is due to an exposure misclassification. On the contrary, it is more likely that the necessarily imperfect historical assessment of exposure has led to an underestimation of the exposure-response association found.

A last limitation of our study is its relatively small size, so that we were only able to show relations between respiratory health and exposure to wood dust because the exposure was relatively high. Our study sheds no light on the possible effects of low exposure on respiratory health, for which larger sample sizes are necessary.

Finally, it should be stressed that the dose-response relations we found cannot be attributed to the inclusion of the historical controls as similar results were found when the analysis was done with only the small group of non-exposed controls.

In conclusion, in woodworkers exposed to beech and oak dust the risk of developing a sore throat because of bronchial responsiveness after inhaling methacholine increases with increasing exposure intensities. Hopefully our longitudinal follow up of these workers will help us to better understand the relevance of these findings.

We thank the woodworkers for their participation and the management staff members of the factories and the occupational physicians for their invaluable help in conducting this study.

1 Ordman D. Bronchial asthma caused by the inhalation of wood dust. Ann Allergy 1949;505:492-6.

2 Chan-Yeung M, Lam S. Occupational asthma. Am Rev Respir Dis 1986;133:686-703.

3 Milne J, Gandevia B. Occupational asthma and rhinitis due to western (Canadian) red cedar (Thuja plicata). Med $\mathcal{f}$ to western (Canadian

4 Brooks SM, Edwards JJ, Apol A, et al. An epidemiological study of workers exposed to western red cedar and other wood dusts. Chest 1981;80(suppl):30S-32S

5 Chan-Yeung M, Barton G, Maclean L, et al. Occupational asthma and rhinitis due to Western red cedar (Thuja plicata). Am Rev Respir Dis 1973;108:1094-102.

6 Chan-Yeung M, Ashley MJ, Corey P. A respiratory survey of cedar mill workers. I. Prevalence of symptoms and pulmonary function abnormalities. F Occup Med 1978;20:323-7.

7 Chan-Yeung M, Lam S, Koener S. Clinical features and natural history of occupational asthma due to western red cedar (Thuja plicata). Am J Med 1982;72:411-15.

8 Chan-Yeung M, Vedal S, Kus J, et al. Symptoms, pulmonary function, and bronchial hyperreactivity in western red cedar workers compared with those in office workers. $A m$ Rev Respir Dis 1984;130:1038-41.

9 Vedal S, Chan-Yeung M, Enarson D, et al. Symptoms and pulmonary function in western red cedar workers related to duration of employment and dust exposure. Arch Environ Health 1986;41:179-83.

10 Chan-Yeung M, Maclean L, Paggiaro PL. Follow-up study of 232 patients with occupational asthma caused by western red cedar (Thuja plicata). 7 Allergy Clin Immunol 1987;79:792-6.

11 Vedal S, Enarson DA, Chan H, et al. A longitudinal study of the occurrence of bronchial hyperresponsiveness in western red cedar workers. Am Rev Respir Dis 1988;137:651-5.

12 Chan-Yeung M, Vedal S, Kennedy SM. A longitudinal study of red cedar sawmill workers. Am Rev Respir Dis 1990;141: A80.

13 Coté J, Kennedy S, Chan-Yeung M. Sensitivity and specificity of PC20 and peak expiratory flow in cedar asthma. $\mathcal{F}$ Allergy Clin Immunol 1990;85:592-8.

14 Kukuh Noertjojo H, Dimich-Ward H, Peelen S, et al. Western red cedar dust exposure and lung function: a dose-response relationship. Am f Respir Crit Care Med 1996;154:968-73.

15 Wild P, Jovanovic B, Massin N. On planning the number of controls in cross-sectional studies using previous studies: an application in occupational epidemiology. Fournal of Epidemiology and Biostatistics 1999;4:93-9.

16 Minette A, Aresini G, Sanna-Randaccio F, et al. Questionnaire de la Communauté Européese du Charbonet et de l'Acier (CECA) pour l'étude des symptômes respiratoires, 3rd ed. Luxembourg: CECA, 1987.

17 Quanjer $\mathrm{Ph} \mathrm{H}$, Tammeling GJ, Cotes JE, et al. Lung volumes and forced ventilatory flows. Report working party standardization of lung function tests. European Community for Steel and Coal. Official statement of the European Respiratory Society. Eur Respir f 1993;6(suppl 16):5-40.

18 Gardner RM. Report of Snowbird workshop on standardization of spirometry. Am Rev Respir Dis 1979;119:831-8.

19 Bohadana AB, Massin N, Wild P, et al. Respiratory symptoms and airway responsiveness in apparently healthy workers exposed to flour dust. Eur Respir f 1995; 7:1070-6.

20 Massin N, Bohadana AB, Wild P, et al. Airway responsiveness, respiratory symptoms, and exposure to soluble oil mist in mechanical workers. Occup Environ Med 1996;53: $748-52$.

21 O'Connor G, Sparrow D, Taylor D, et al. Analysis of doseresponse curves to methacholine. An approach suitable for population studies. Am Rev Respir Dis 1987;128:1412-17.

22 SAS Institute. SAS/SAT user's guide, version 6, 4th ed. Vol 2. Cary, NC: SAS Institute; 1989:846.

23 Maciejewska A, Wojtezak J, Bielichowska-Cibula G, et al. Biological effect of wood dust. Medycyny Pracy 1993;44: 277-88.

24 CIRCULAIRE DRT n 93-18 du 12/07/1993. In: INRS Cahiers de notes documentaires $\mathrm{n}^{\circ} 153,4$ ème trimestre 1993: 566.

25 American Conference of Governmental Industrial Hygienists. Documentation of the threshold limit values and biological ists. Documentation of the threshold limit values and biological

26 Directoraat-General van de Arbeid Dutch Expert Committee for Occupational Standards. Health-based recommended occupational exposure limit for wood dust.Den Hag: DECOS, 1992. (Report number RA 8/91.)

27 Dahlqvist M, Johard U, Alexandersson R, et al. Lung function and precipitating antibodies in low exposed wood trimmers in Sweden. Am f Ind Med 1992;21:549-59.

28 Malmberg PO, Rask-Andersen A, Larsson KA, et al. Increased bronchial responsiveness in workers sawing Scots pine. Am f Respir Crit Care Med 1996;153:948-52.

29 Sosman A, Schlueter DP, Fink JN, et al. Hypersensitivity to wood dust. N Engl f Med 1969;281:977-80.

30 Malo J-L, Cartier A, Desjardins A, et al. Occupational asthma caused by oak wood dust. Chest 1995;108:856-8.

31 Hausen BM. Woods injurious to human health: a manual. Berlin: Walter de Gruyter, 1981.

32 Massin N, Bohadana AB, Wild P, et al. Respiratory symptoms and bronchial responsiveness in lifeguards exposed to nitrogen trichloride in indoor swimming pools. Occup Environ Med 1998;55:258-63.

33 Scheeper B, Kromhout H, Boleij JSM. Wood-dust exposure during wood working processes. Ann Occup Hyg 1994;39: $141-54$. 